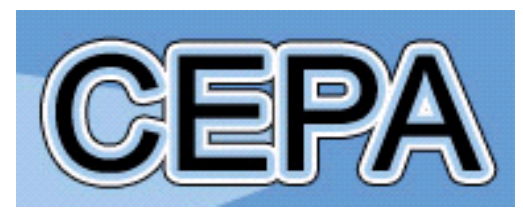

Centre for Efficiency and Productivity Analysis

Working Paper Series

No. WP10/2019

Dual Productivity Analysis: A Konüs/Shephard Approach

E. Grifell-Tatjé \& C. A. K. Lovell

Date: August 2019

School of Economics

University of Queensland

St. Lucia, Qld. 4072

Australia

ISSN No. 1932 - 4398 


\title{
Dual Productivity Analysis: A Konüs/Shephard Approach
}

\author{
E. Grifell-Tatjé, Universitat Autònoma de Barcelona (emili.grifell@uab.cat) \\ C. A. K. Lovell, University of Queensland (k.lovell@uq.edu.au)
}

\begin{abstract}
A primal (or direct) productivity index is conventionally defined as the ratio of an output quantity index to an input quantity index. There have been attempts in the literature to define and implement dual and indirect productivity indexes based on price changes rather than quantity changes. Although dual and indirect productivity indexes share a common motivation, the measurement of productivity change when prices are measured more accurately than quantities, they differ analytically, from one another and from primal productivity indexes. We introduce a new dual productivity index, based on contributions of Konüs and Shephard, and we compare our dual productivity index with a primal productivity index based on the work of Malmquist. We also compare these two theoretical productivity indexes with analogous empirical Fisher productivity indexes. We provide an empirical application to US agricultural productivity growth.
\end{abstract}

Keywords: dual and primal productivity indexes, price distance functions, agricultural productivity

JEL Codes: D24, D33

\section{Acknowledgements}

We are grateful to the Generalitat de Catalunya project 2017SGR-1036 and the Spanish Ministerio de Economía, Industria y Competitividad, project ECO2017-86054C3-1-RX, for their generous financial support of this research. 


\section{Dual Productivity Analysis: A Konüs/Shephard Approach}

\section{Introduction}

In his post-war review of US productivity trends, Evans (1947; 221-222) stressed not just the magnitude of productivity changes but also their economic significance, reporting that workers had enjoyed the fruits of productivity growth (which he called technical progress) through wage increases and price declines. Soon thereafter Davis (1955; Chs. 1,5), whose interest centred on the performance of an individual business rather than that of an aggregate economy, argued that business productivity growth benefits customers through lower prices, labour and suppliers of materials through higher remuneration, and owners of the business through higher retained earnings. ${ }^{1}$ In his monumental study of productivity trends in the US economy in the first half of the $20^{\text {th }}$ century, Kendrick $(1961 ; 111)$ echoed the issues raised by Evans and Davis, noting that "[i]f productivity advances, wage rates and capital return necessarily rise in relation to the general product price level, since this is the means whereby the fruits of productivity gains are distributed to workers and investors by the market mechanism." Kendrick illustrated his claim by calculating productivity growth in the US economy over various time periods using the ratio of total factor price and average product price. Returning to the level of an individual business, Eldor and Sudit (1981) analysed the distribution of productivity gains among consumers, workers and owners at "a major corporation". This early awareness of the distributional implications of productivity change, at both business and aggregate levels, and the emphasis of Kendrick on necessity, suggest the possibility of using price changes rather than quantity changes to measure productivity change.

Fourastié $(1957,1962)$ was among the first to infer productivity change from price changes. Noting that both the objective and the result of productivity growth were to "...bring down selling prices and consequently speed up social progress and more particularly raise living standards and the purchasing power of wages and salaries," $(1957 ; 12)$ Fourastié developed a crude mathematical model in which productivity was expressed as the ratio of labour's wage to product price, assuming that the quantities of all other inputs could be expressed in terms of labour hours. He proceeded to argue that in some circumstances prices are easier to measure than quantities, especially at the aggregate level and over long time periods, and he provided a variety of empirical applications in which he used changes in labour's wage and product prices to estimate productivity change. Fourastié referred to the use of price changes to measure productivity change as the "indirect" approach to productivity measurement. ${ }^{2}$

Eventually analysis began complementing intuition and evidence, beginning with Siegel (1955; 53), who was the first to state conditions under which a price-based productivity index coincides with a quantity-based productivity index. Arguing that the impact of productivity growth "... is to make output cheap compared to input..." led him 
to refine Fourastié's approach by defining an indirect productivity index as the ratio of a cost index to a product price index. Later Siegel $(1961 ; 27)$, Vincent $(1961 ; 12-13)$ and Puiseux and Bernard $(1965,1966)$ were more analytically precise. Siegel showed that (i) if the product test is satisfied for outputs, so that $Y \times P=V$, with $Y$ and $P$ indicating quantity and price indexes for output, and $\mathrm{V}$ indicating a "value index" for output, by which he meant revenue change $\mathrm{R}^{\mathrm{t}+1} / \mathrm{R}^{\mathrm{t}}$; and (ii) if the product test is satisfied for inputs, so that $X \times W=U$, with $X$ and $W$ indicating quantity and price indexes for input, and $U$ indicating a "value index" for input, by which he meant cost change $\mathrm{C}^{\mathrm{t}+1} / \mathrm{C}^{\mathrm{t}}$; then $\mathrm{PY} / \mathrm{WX}=\mathrm{V} / \mathrm{U}$, in which $\mathrm{PY} / \mathrm{WX}$ is profitability change, or Georgescu-Roegen's (1951) "return to the dollar". Additionally if $R^{t}=C^{t}, t=0,1$, it follows that $\mathrm{V}=\mathrm{U}$, and consequently a price-based productivity index W/P coincides with a quantity-based productivity index $\mathrm{Y} / \mathrm{X}$. Siegel illustrated this result with a Paasche dual productivity index $\mathrm{W}_{\mathrm{P}} / \mathrm{PP}_{\mathrm{P}}$ and a Laspeyres primal productivity index YปXL. This final assertion is correct but incomplete, however, and we show below that, conditional on satisfaction of the two product tests, a zero profit condition $R^{t}=C^{t}, t=0,1$, is sufficient but not necessary for $R^{t+1} / R^{t}=C^{t+1} / C^{t}$, and consequently for equality of dual and primal productivity indexes. The historical development and decomposition of profitability change into productivity change and price recovery change (the reciprocal of W/P) is detailed in Grifell-Tatjé and Lovell (2015; Chs. 2,3). ${ }^{3}$

More recently Shapiro (1987), Roeger (1995), Hsieh (2002), Aiyar and Dalgaard (2005) and Fernald and Neiman (2011) have spawned a rapidly growing literature that uses price changes to estimate productivity change, primarily in the context of uncovering the sources of economic growth. Hsieh's motivation arose from anomalies he uncovered in previous research into the growth experience of East Asian countries, Singapore in particular. The methodology underlying this literature is dual productivity accounting, as proposed by Jorgenson and Griliches (1967), in which primal productivity change is estimated as the revenue share-weighted sum of the rates of change of output quantities minus (or divided by) the cost share-weighted sum of the rates of change of input quantities, and dual productivity change is estimated as the cost share-weighted sum of the rates of change of input prices minus (or divided by) the revenue share-weighted sum of the rates of change of output prices. In the Jorgenson and Griliches set-up the accounting identity forces equality between revenue and expenditure in each period, and thus between primal and dual measures of productivity change. However the principal finding of the subsequent empirical literature cited above is that primal and dual estimates of productivity change can and do differ, because the accounting identity can and does break down for a number of reasons. Hsieh mentions four potential sources of divergence: imperfect competition, short-run adjustment costs, omitted or mis-measured inputs (or outputs; Hsieh's model has a single aggregate output), and inconsistencies between the sources of quantity and price data. Fernald and Neiman add another potential source of divergence: heterogeneous tax treatment and capital subsidies arising from government policy interventions. 
Our dual approach is similar in spirit, but very different in assumptions, from the dual productivity accounting approach developed by Jorgenson and Griliches. An important assumption underpinning the productivity accounting approach is that producers optimise, with marginal rates of input substitution equalling input price ratios and marginal rates of output transformation equalling output price ratios. This equilibrium assumption justifies replacement of theoretical but unobservable input and output production elasticities with observable input cost shares and output revenue shares. In sharp contrast, although our dual approach also requires quantity data, the quantity data are not linked to an assumption of optimising behaviour, being based on distance functions rather than minimum cost and maximum revenue functions.

Our dual approach also differs from an indirect approach developed by Shephard (1974) and extended to indirect productivity measurement by Färe et al. (1992) and Färe and Grosskopf (1994). Whereas our approach is simultaneously output- and input-oriented, this indirect approach has a single orientation, either a costconstrained output (or revenue) maximisation orientation in which output quantities are the choice variables, or a revenue-constrained input (or cost) minimisation orientation, in which input quantities are the choice variables. It is based on distance functions, but the distance functions are defined on either cost-deflated input price and output quantity space or revenue-deflated output price and input quantity space, and so it requires quantity information. However as a distance function based approach, it does not require an assumption of optimising behaviour, and perhaps consequently the cost-constrained output maximisation orientation has proved particularly useful for analysing performance in the provision of public services such as education, health care or public safety, in which output prices are missing or heavily subsidized and budgets (rather than resources) are wholly or partly allocated by agencies.

Our dual approach is inspired by the Konüs (1924) cost of living index, the ratio of the minimum cost of producing a given output quantity vector at two different input price vectors. In this set-up input prices are exogenous, and the choice variables are input quantities. We then exploit Shephard's (1970) interpretation of a (minimum) cost function as a distance function in input price space. This insight leads to a reinterpretation of the Konüs cost of living index, in which input quantities are the choice variables, as an input price index, in which input prices are the choice variables. Konüs did not consider the output side of the production relation, but Shephard did, reinterpreting a (maximum) revenue function as a distance function in output price space. This re-interpretation enables us to define the ratio of the maximum revenue obtainable from a given input quantity vector at two different output price vectors as an output price index, in which output prices are the choice variables. Finally, our Konüs-Shephard dual productivity index is defined as the ratio of the input price index to the output price index, with its reciprocal defining a price recovery index. This dual productivity index is consistent with the interpretations of productivity change appearing in the quotes of Kendrick and, especially, Siegel (1955) above. 
The rest of our paper is structured as follows. In Section 2 we develop our dual productivity index. In Section 3 we relate our dual productivity index to a primal productivity index based on the work of Malmquist (1953) in a consumer context, as transferred to a producer context by Diewert (1992; 348) and Bjurek (1996; 308). In contrast to Jorgenson and Griliches $(1967 ; 252)$, who note that their dual and primal productivity indexes "...are dual to each other and are equivalent...", we find no general equivalence between our Konüs-Shephard dual productivity index and a Malmquist primal productivity index. In our analytical framework equivalence requires the input and output price mixes and the input and output quantity mixes to vary in offsetting ways, a razor's edge condition that is unlikely to be satisfied in any empirical setting. In Section 4 we develop a procedure with which to implement our dual productivity index with time series data rather than panel data. In Section 5 we describe our time series data set, which consists of price indexes and implicit quantity indexes for three inputs and three outputs in US agriculture over the 68 year period 1948-2015, and we report our empirical findings. We find estimated productivity growth based on our Konüs-Shephard dual productivity index to differ from an estimate based on a primal Malmquist productivity index, although the two are very close, and they bound estimates of the US Department of Agriculture based on a Fisher productivity index. Section 6 concludes.

\section{Analytical Foundations}

We follow Shephard (1970) to develop a dual input price index that we use to decompose cost change in Section 2.1, and we develop a dual output price index that we use to decompose revenue change in Section 2.2, following similar procedures. A dual productivity index is defined as the ratio of the two dual price indexes, and is the reciprocal of a price recovery index, which we use to decompose profitability change in Section 2.3. The decompositions of cost change, revenue change and profitability change are essential to uncovering the relationship between dual and primal productivity indexes.

We use the following notation: $y \in \mathfrak{R}_{+}^{M}$ and $x \in \mathfrak{R}_{+}^{N}$ are quantity vectors of outputs and inputs, the prices of which are $p \in \mathfrak{R}_{++}^{M}$ and $w \in \mathfrak{R}_{++}^{N}$. The production set $T=\{(x, y): x$ can produce $y\}$ is closed, bounded and satisfies weak disposability of $x$ and $y$. Input sets are $L(y)=\{x:(y, x) \in T\}, y \in \mathfrak{R}_{+}^{M}$, and output sets are $P(x)=\{y:(x, y)$ $\in T\}, x \in \mathfrak{R}_{+}^{N}$. Input distance functions $D_{i}(y, x)=\max _{\lambda}\{\lambda:(x / \lambda) \in L(y)\}, y \in \mathfrak{R}_{+}^{M}$, are homogeneous of degree +1 in $x$, with $D_{i}(y, x) \geqq 1$ if and only if $x \in L(y)$. The cost function $c(y, w)=\min _{x}\left\{w^{\top} x: D_{i}(y, x) \geqq 1\right\}$ is homogeneous of degree +1 in $w$. Output distance functions $D_{o}(x, y)=\min _{\theta}\{\theta:(y / \theta) \in P(x)\}, x \in \mathfrak{R}_{+}^{N}$, are homogeneous of degree +1 in $y$, with $D_{o}(x, y) \leqq 1$ if and only if $y \in P(x)$. The revenue function $r(x, p)=\max \left\{p^{\top} y: D_{o}(x, y)\right.$ $\leqq 1\}$ is homogeneous of degree +1 in $p$. 


\subsection{A Dual Input Price Index and the Decomposition of Cost Change}

Shephard (1970; Chapter 5) introduced the cost structure of production technology, defined as the family of subsets of $w \in \mathfrak{R}_{++}^{N}$ given by

$$
\mathfrak{L}(y)=\{w: c(y, w) \geqq 1, w>0\},
$$

in which the cost function $c(y, w)$ is a distance function for the cost structure $\mathfrak{L}(y)$. $\mathfrak{L}(y)$ inherits its properties from those of the production technology, and we follow Shephard by assuming $\mathfrak{L}(y)$ satisfies disposability, closure and convexity properties. Shephard defined an input price vector $w \in \mathfrak{L}(y)$ as efficient if and only if it belongs to the efficient subset of $\mathfrak{L}(y)$ for which $c\left(y, w^{\prime}\right)<1 \forall w^{\prime} \leq w$.

Since $c(y, w)$ is a distance function in input price space we change notation and define a dual input price distance function on $\mathfrak{L}(y)$ as

$$
\left.D_{w}(y, w)=\max _{\delta}\left\{\delta: c\left(y, \frac{w}{\delta}\right)\right\} \geqq 1\right\},
$$

which seeks the maximum radial reduction in $w$ such that $c(y, w) \geqq 1$. Färe (1984) defined a measure of input price efficiency as the radial distance of an input price vector to Shephard's efficient subset of $\mathfrak{L}(y)$ given by $F_{w}(y, w)=\min _{\gamma}\{\gamma: \gamma w \in$ $\mathfrak{L}(y)\}=1 / D_{w}(y, w)$. The dual input price distance function $D_{w}(y, w)$ has the same properties as its primal input quantity distance function counterpart $D_{i}(y, x)$, with input prices replacing input quantities.

Next we use the dual input price distance function to define a dual input price index, which we then use to decompose cost change. We define a Konüs base period dual input price index as

$$
W_{K}^{0}\left(y^{0}, w^{1}, w^{0}\right)=\frac{D_{w}^{0}\left(y^{0}, w^{1}\right)}{D_{w}^{0}\left(y^{0}, w^{0}\right)^{\prime}}
$$

which is non-negative, non-decreasing and homogeneous of degree +1 in $w$. $W_{K}^{0}\left(y^{0}, w^{1}, w^{0}\right)$ is independent of $y^{0}$ if, and only if, base period production technology is input homothetic.

We use $W_{K}^{0}\left(y^{0}, w^{1}, w^{0}\right)$ to decompose cost change, beginning with

$$
\frac{C^{1}}{C^{0}}=W_{K}^{0}\left(y^{0}, w^{1}, w^{0}\right) \times X I^{0}\left(y^{0}, x^{1}, x^{0}, w^{1}, w^{0}\right),
$$


in which $X I^{0}\left(y^{0}, x^{1}, x^{0}, w^{1}, w^{0}\right)$ is a base period implicit input quantity index. Transferring a strategy employed by Grifell-Tatjé and Lovell $(2015,2016)$ from quantity space to price space, we decompose $X I^{0}\left(y^{0}, x^{1}, x^{0}, w^{1}, w^{0}\right)$ as follows

$$
\begin{aligned}
X I^{0}\left(y^{0}, x^{1}, x^{0}, w^{1}, w^{0}\right) & =\frac{C^{1} / C^{0}}{W_{K}^{0}\left(y^{0}, w^{1}, w^{0}\right)} \\
& =\frac{w^{1 T} x^{1}}{w^{1 T} x^{0}} \times \frac{x^{0 T} w^{1}}{x^{0 T} w^{0}} \times \frac{D_{w}^{0}\left(y^{0}, w^{0}\right)}{D_{w}^{0}\left(y^{0}, w^{1}\right)} \\
= & X_{P} \times W S_{L}\left(y^{0}, x^{0}, w^{1}, w^{0}\right),
\end{aligned}
$$

in which $X_{P}=w^{1 T} x^{1} / w^{1 T} x^{0}$ is a Paasche input quantity index and

$$
W S_{L}\left(y^{0}, x^{0}, w^{1}, w^{0}\right)=\frac{x^{0 T}\left[w^{1} / D_{w}^{0}\left(y^{0}, w^{1}\right)\right]}{x^{0 T}\left[w^{0} / D_{w}^{0}\left(y^{0}, w^{0}\right)\right]} \gtreqless 1
$$

is a Shephard-Laspeyres input price mix index with input prices $w^{1}$ and $w^{0}$ radially expanded or contracted to Shephard's base period efficient subset. This index evaluates the impact on cost of a change in the input price mix from $w^{0}$ to $w^{1}$. If base period input quantities are less (more) expensive when evaluated at efficient base period input prices than at efficient comparison period input prices, then $W S_{L}\left(y^{0}, x^{0}, w^{1}, w^{0}\right)>(<) 1$. Since $D_{w}^{0}(y, w)$ is homogeneous of degree +1 in $w$, the input price mix index has a value of unity, and makes no contribution to cost change, if, and only if, $w^{1}=\lambda w^{0}, \lambda>0$, i.e. if and only if the input price mix is unchanged from base period to comparison period. $W S_{L}\left(y^{0}, x^{0}, w^{1}, w^{0}\right)$ is independent of $y^{0}$ if and only if base period technology is input homothetic.

Inserting (5) into (4) generates a base period decomposition of cost change

$$
\frac{C^{1}}{C^{0}}=W_{K}^{0}\left(y^{0}, w^{1}, w^{0}\right) \times X_{P} \times W S_{L}\left(y^{0}, x^{0}, w^{1}, w^{0}\right) .
$$

Thus cost change can be expressed as the product of a Konüs base period dual input price index, a Paasche input quantity index, and a Shephard-Laspeyres input price mix index. $W_{K}^{0}\left(y^{0}, w^{1}, w^{0}\right)$ and $X_{P}$ satisfy the product test with $C^{1 /} C^{0}$ If, and only if, $W S_{L}\left(y^{0}, x^{0}, w^{1}, w^{0}\right)=1$. Otherwise cost change has three drivers.

It is straightforward to repeat the foregoing analysis using a Konüs comparison period dual input price index 


$$
W_{K}^{1}\left(y^{1}, w^{1}, w^{0}\right)=\frac{D_{w}^{1}\left(y^{1}, w^{1}\right)}{D_{w}^{1}\left(y^{1}, w^{0}\right)^{\prime}}
$$

which is independent of $y^{1}$ if, and only if, comparison period production technology is input homothetic. This generates the cost change decomposition

$$
\frac{C^{1}}{C^{0}}=W_{K}^{1}\left(y^{1}, w^{1}, w^{0}\right) \times X I^{1}\left(y^{1}, x^{1}, x^{0}, w^{1}, w^{0}\right),
$$

in which $X I^{1}\left(y^{1}, x^{1}, x^{0}, w^{1}, w^{0}\right)$ is a comparison period implicit input quantity index. This index can be decomposed as

$$
\begin{aligned}
X I^{1}\left(y^{1}, x^{1}, x^{0}, w^{1}, w^{0}\right) & =\frac{C^{1} / C^{0}}{W_{K}^{1}\left(y^{1}, w^{1}, w^{0}\right)} \\
& =\frac{w^{0 T} x^{1}}{w^{0 T} x^{0}} \times \frac{x^{1 T} w^{1}}{x^{1 T} w^{0}} \times \frac{D_{w}^{1}\left(y^{1}, w^{0}\right)}{D_{w}^{1}\left(y^{1}, w^{1}\right)} \\
=X_{L} & \times W S_{P}\left(y^{1}, x^{1}, w^{1}, w^{0}\right),
\end{aligned}
$$

in which $X_{L}=w^{0 T} x^{1} / w^{0 T} x^{0}$ is a Laspeyres input quantity index and

$$
W S_{P}\left(y^{1}, x^{1}, w^{1}, w^{0}\right)=\frac{x^{1 T}\left[w^{1} / D_{w}^{1}\left(y^{1}, w^{1}\right)\right]}{x^{1 T}\left[w^{0} / D_{w}^{1}\left(y^{1}, w^{0}\right)\right]} \lesseqgtr 1
$$

is a Shephard-Paasche input price mix index with input prices $w^{1}$ and $w^{0}$ radially expanded or contracted to Shephard's comparison period efficient subset. This index also evaluates the impact on cost of a change in the input price mix from $w^{0}$ to $w^{1}$. If comparison period inputs are less (more) expensive when evaluated at efficient comparison period input prices than at efficient base period input prices, then $W S_{P}\left(y^{1}, x^{1}, w^{1}, w^{0}\right)<(>) 1 . W S_{P}\left(y^{1}, x^{1}, w^{1}, w^{0}\right)$ is independent of $y^{1}$ if, and only if, comparison period technology is input homothetic.

Inserting (10) into (9) yields a comparison period cost change decomposition

$$
\frac{C^{1}}{C^{0}}=W_{K}^{1}\left(y^{1}, w^{1}, w^{0}\right) \times X_{L} \times W S_{P}\left(y^{1}, x^{1}, w^{1}, w^{0}\right),
$$


which states that cost change also can be expressed as the product of a Konüs comparison period dual input price index, a Laspeyres input quantity index, and a Shephard-Paasche input price mix index. Since $D_{w}^{1}(y, w)$ is homogeneous of degree +1 in $w$, the input price mix index has a value of unity if, and only if, the input price mix remains constant, in which case $W_{K}^{1}\left(y^{1}, w^{1}, w^{0}\right)$ and $X_{L}$ satisfy the product test with $C^{1} / C^{0}$.

Taking the geometric mean of (7) and (12) generates the cost change decomposition

$$
\begin{aligned}
& \frac{C^{1}}{C^{0}}=\left[W_{K}^{0}\left(y^{0}, w^{1}, w^{0}\right) \times W_{K}^{1}\left(y^{1}, w^{1}, w^{0}\right)\right]^{1 / 2} \times\left[X_{P} \times X_{L}\right]^{1 / 2} \\
& \quad \times\left[W S_{L}\left(y^{0}, x^{0}, w^{1}, w^{0}\right) \times W S_{P}\left(y^{1}, x^{1}, w^{1}, w^{0}\right)\right]^{1 / 2} \\
& =W_{K}\left(y^{1}, y^{0}, w^{1}, w^{0}\right) \times X_{F} \times W S_{F}\left(y^{1}, y^{0}, x^{1}, x^{0}, w^{1}, w^{0}\right),
\end{aligned}
$$

in which $X_{F}$ is a Fisher input quantity index. Thus cost change is expressed as the product of a Konüs dual input price index, a Fisher input quantity index, and a Shephard-Fisher input price mix index. The Konüs dual input price index is independent of output quantities if both base period and comparison period technologies are input homothetic. It satisfies the product test with the Fisher input quantity index if, and only if, the input price mix index is unity, which does not require an unchanged input price mix since it does not require either of its base period and comparison period components to be unity. Thus $W S_{L}\left(y^{0}, x^{0}, w^{1}, w^{0}\right)=$ $W S_{P}\left(y^{1}, x^{1}, w^{1}, w^{0}\right)=1$ is sufficient, but not necessary, for satisfaction of the product test. A necessary and sufficient condition is $W S_{L}\left(y^{0}, x^{0}, w^{1}, w^{0}\right)=$ $1 / W S_{P}\left(y^{1}, x^{1}, w^{1}, w^{0}\right) .^{4}$

\subsection{A Dual Output Price Index and the Decomposition of Revenue Change}

Again following Shephard (1970; Chapter 10), we define the revenue structure of production technology as the family of subsets of $p \in \mathfrak{R}_{++}^{M}$ given by

$$
\mathcal{P}(x)=\{p: r(x, p) \leqq 1, p>0\} .
$$


$\mathcal{P}(x)$ inherits its properties (disposability, closure and convexity) from those of the primal production technology, and the primal revenue function $r(x, p)$ is a distance function for the revenue structure $\mathcal{P}(x)$.

An output price distance function is defined on $\mathcal{P}(x)$ as

$$
D_{p}(x, p)=\min _{v}\left\{v: r\left(x, \frac{p}{v}\right) \leqq 1\right\}
$$

and a radial measure of output price efficiency is defined as $F_{p}(x, p)=1 / D_{p}(x, p)$. The dual output price distance function $D_{p}(x, p)$ has the same properties as its primal output quantity counterpart $D_{o}(x, y)$, with output prices replacing output quantities.

A Konüs base period dual output price index is defined as

$$
P_{K}^{0}\left(x^{0}, p^{1}, p^{0}\right)=\frac{D_{p}^{0}\left(x^{0}, p^{1}\right)}{D_{p}^{0}\left(x^{0}, p^{0}\right)^{\prime}}
$$

which is non-negative, non-decreasing and homogeneous of degree $+1 . P_{K}^{0}\left(x^{0}, p^{1}, p^{0}\right)$ is independent of $x^{0}$ if and only if base period production technology is output homothetic.

We decompose revenue change as

$$
\frac{R^{1}}{R^{0}}=P_{K}^{0}\left(x^{0}, p^{1}, p^{0}\right) \times Y I^{0}\left(x^{0}, y^{1}, y^{0}, p^{1}, p^{0}\right),
$$

in which $Y I^{0}\left(x^{0}, y^{1}, y^{0}, p^{1}, p^{0}\right)$ is a base period implicit output quantity index that can be decomposed as

$$
\begin{aligned}
Y I^{0}\left(x^{0}, y^{1}, y^{0}, p^{1}, p^{0}\right) & =\frac{R^{1} / R^{0}}{P_{K}^{0}\left(x^{0}, p^{1}, p^{0}\right)} \\
& =\frac{p^{1 T} y^{1}}{p^{1 T} y^{0}} \times \frac{y^{0 T} p^{1}}{y^{0 T} p^{0}} \times \frac{D_{p}^{0}\left(x^{0}, p^{0}\right)}{D_{p}^{0}\left(x^{0}, p^{1}\right)} \\
& =Y_{P} \times P S_{L}\left(x^{0}, y^{0}, p^{1}, p^{0}\right),
\end{aligned}
$$

in which $Y_{p}=p^{1 T} y^{1} / p^{1 T} y^{0}$ is a Paasche output quantity index and 


$$
P S_{L}\left(x^{0}, y^{0}, p^{1}, p^{0}\right)=\frac{y^{0 T}\left[p^{1} / D_{p}^{0}\left(x^{0}, p^{1}\right)\right]}{y^{0 T}\left[p^{0} / D_{p}^{0}\left(x^{0}, p^{0}\right)\right]} \lesseqgtr 1
$$

is a Shephard-Laspeyres output price mix index that evaluates the impact on revenue of a change in the output price mix. Inserting (18) into (17) generates a base period decomposition of revenue change

$$
\frac{R^{1}}{R^{0}}=P_{K}^{0}\left(x^{0}, p^{1}, p^{0}\right) \times Y_{P} \times P S_{L}\left(x^{0}, y^{0}, p^{1}, p^{0}\right) .
$$

Since $D_{p}^{0}(x, p)$ is homogeneous of degree +1 in $p, P S_{L}\left(x^{0}, y^{0}, p^{1}, p^{0}\right)=1$ if, and only if, $p^{1}=\lambda p^{0}$, with $\lambda>0$, and then $R^{1} / R^{0}=P_{K}^{0}\left(x^{0}, p^{1}, p^{0}\right) \times Y_{P}$. Thus $P_{K}^{0}\left(x^{0}, p^{1}, p^{0}\right)$ satisfies the product test with $Y_{P}$ if, and only if, the output price mix is unchanged between base and comparison periods. Otherwise revenue change has three drivers.

Moving from base period to comparison period, a Konüs comparison period dual output price index is defined as

$$
P_{K}^{1}\left(x^{1}, p^{1}, p^{0}\right)=\frac{D_{p}^{1}\left(x^{1}, p^{1}\right)}{D_{p}^{1}\left(x^{1}, p^{0}\right)}
$$

which is independent of $x^{1}$ if and only if comparison period production technology is output homothetic. We decompose revenue change as

$$
\frac{R^{1}}{R^{0}}=P_{K}^{1}\left(x^{1}, p^{1}, p^{0}\right) \times Y I^{1}\left(x^{1}, y^{1}, y^{0}, p^{1}, p^{0}\right),
$$

in which $Y I^{1}\left(x^{1}, y^{1}, y^{0}, p^{1}, p^{0}\right)$ is a comparison period implicit output quantity index. We express this index as

$$
\begin{aligned}
Y I^{1}\left(x^{1}, y^{1}, y^{0}, p^{1}, p^{0}\right)= & \frac{R^{1} / R^{0}}{P_{K}^{1}\left(x^{1}, p^{1}, p^{0}\right)} \\
& =\frac{p^{0 T} y^{1}}{p^{0 T} y^{0}} \times \frac{y^{1 T} p^{1}}{y^{1 T} p^{0}} \times \frac{D_{p}^{1}\left(x^{1}, p^{0}\right)}{D_{p}^{1}\left(x^{1}, p^{1}\right)} \\
& =Y_{L} \times P S_{P}\left(x^{1}, y^{1}, p^{1}, p^{0}\right),
\end{aligned}
$$

in which $Y_{L}=p^{0 T} y^{1} / p^{0 T} y^{0}$ is a Laspeyres output quantity index and 


$$
P S_{P}\left(x^{1}, y^{1}, p^{1}, p^{0}\right)=\frac{y^{1 T}\left[p^{1} / D_{p}^{1}\left(x^{1}, p^{1}\right)\right]}{y^{1 T}\left[p^{0} / D_{p}^{1}\left(x^{1}, p^{0}\right)\right]} \gtreqless 1
$$

is a Shephard-Paasche output price mix index. Substituting (23) into (22) generates a second decomposition of revenue change

$$
\frac{R^{1}}{R^{0}}=P_{K}^{1}\left(x^{1}, p^{1}, p^{0}\right) \times Y_{L} \times P S_{P}\left(x^{1}, y^{1}, p^{1}, p^{0}\right),
$$

the product of a Konüs comparison period dual output price index, a Laspeyres output quantity index, and a Shephard-Paasche output price mix index that provides a second measure of the impact on revenue of a change in the output price mix. A Konüs comparison period dual output price index satisfies the product test with a Laspeyres output quantity index if, and only if, the output price mix is unchanged between base and comparison periods.

Taking the geometric mean of (20) and (25) generates the final decomposition of revenue change

$$
\begin{aligned}
\frac{C^{1}}{C^{0}}=\left[P_{K}^{0}\left(x^{0}, p^{1}, p^{0}\right)\right. & \left.\times P_{K}^{1}\left(x^{1}, p^{1}, p^{0}\right)\right]^{1 / 2} \times\left[Y_{P} \times Y_{L}\right]^{1 / 2} \\
& \times\left[P S_{L}\left(x^{0}, y^{0}, p^{1}, p^{0}\right) \times P S_{P}\left(x^{1}, y^{1}, p^{1}, p^{0}\right)\right]^{1 / 2} \\
= & P_{K}\left(x^{1}, x^{0}, p^{1}, p^{0}\right) \times Y_{F} \times P S_{F}\left(x^{1}, x^{0}, y^{1}, y^{0}, p^{1}, p^{0}\right) .
\end{aligned}
$$

Revenue change is expressed as the product of a Konüs dual output price index, a Fisher output quantity index, and a Shephard-Fisher output price mix index. The Konüs dual output price index is independent of input quantities if both base period and comparison period technologies are output homothetic. It satisfies the product test with the Fisher output quantity index if, and only if, $P S_{F}\left(x^{1}, x^{0}, y^{1}, y^{0}, p^{1}, p^{0}\right)=1$. Thus $P S_{L}\left(x^{0}, y^{0}, p^{1}, p^{0}\right)=P S_{P}\left(x^{1}, y^{1}, p^{1}, p^{0}\right)=1$ is sufficient, but not necessary, for satisfaction of the product test, a necessary and sufficient condition being $P S_{L}\left(x^{0}, y^{0}, p^{1}, p^{0}\right)=1 / P S_{P}\left(x^{1}, y^{1}, p^{1}, p^{0}\right)$. 


\subsection{A Price Recovery Index and the Decomposition of Profitability Change}

Combining the geometric mean decomposition of cost change in Section 2.1 with the geometric mean decomposition of revenue change in Section 2.2 generates the following decomposition of profitability change

$$
\frac{R^{1} / C^{1}}{R^{0} / C^{0}}=\frac{P_{K}\left(x^{1}, x^{0}, p^{1}, p^{0}\right)}{W_{K}\left(y^{1}, y^{0}, w^{1}, w^{0}\right)} \times \frac{Y_{F}}{X_{F}} \times \frac{P S_{F}\left(x^{1}, x^{0}, y^{1}, y^{0}, p^{1}, p^{0}\right)}{W S_{F}\left(y^{1}, y^{0}, x^{1}, x^{0}, w^{1}, w^{0}\right)} .
$$

Thus profitability change is the product of a Konüs dual price recovery index, a Fisher productivity index, and a Shephard-Fisher price mix index. A Konüs dual price recovery index is independent of all quantities if, and only if, both base period and comparison period technologies are inversely homothetic. It satisfies the product test with the Fisher productivity index if, and only if the price mix index is unity.

Solving (27) for the Konüs dual productivity index, which is the reciprocal of the Konüs dual price recovery index, yields

$$
\frac{W_{K}\left(y^{1}, y^{0}, w^{1}, w^{0}\right)}{P_{K}\left(x^{1}, x^{0}, p^{1}, p^{0}\right)}=\rho\left(y^{1}, y^{0}, x^{1}, x^{0}, p^{1}, p^{0}, w^{1}, w^{0}\right) \times \frac{Y_{F}}{X_{F}}
$$

in which

$$
\rho\left(y^{1}, y^{0}, x^{1}, x^{0}, p^{1}, p^{0}, w^{1}, w^{0}\right)=\frac{P S_{F}\left(x^{1}, x^{0}, y^{1}, y^{0}, p^{1}, p^{0}\right) / W S_{F}\left(y^{1}, y^{0}, x^{1}, x^{0}, w^{1}, w^{0}\right)}{\left(R^{1} / C^{1}\right) /\left(R^{0} / C^{0}\right)} .
$$

Expression (28) provides the relationship between the Konüs dual productivity index and a Fisher productivity index. The numerator of $\rho$ takes a value of one if the Fisher price mix index is unity, a requirement that imposes restrictions on the behaviour of output and input prices. And since $R^{h}=\left(1+g^{h}\right) C^{h}, h=1,0$ where $g$ expresses the margin of the production unit, the denominator takes a value of one when the margin is unchanged which, as we noted in our discussion of Siegel (1961) in Section 1, does not require $R^{h}=C^{h}, h=1,0$. This requirement does, however, preclude any trend in market power. Both conditions are most likely to occur when the analysis is conducted over short time periods or in sectors not subject to frequent disruptive changes to the two price mixes. It is possible to test the hypothesis that $\rho\left(y^{1}, y^{0}, x^{1}, x^{0}, p^{1}, p^{0}, w^{1}, w^{0}\right)=1, \quad$ and therefore that $W_{K}\left(y^{1}, y^{0}, w^{1}, w^{0}\right) / P_{K}\left(x^{1}, x^{0}, p^{1}, p^{0}\right)=Y_{F} / X_{F}$.

Also since $\frac{Y_{F}}{X_{F}}=\frac{R^{1} / C^{1}}{R^{0} / C^{0}} \times \frac{W_{F}}{P_{F}}$ it follows that 


$$
\frac{W_{K}\left(y^{1}, y^{0}, w^{1}, w^{0}\right)}{P_{K}\left(x^{1}, x^{0}, p^{1}, p^{0}\right)}=\frac{P S_{F}\left(x^{1}, x^{0}, y^{1}, y^{0}, p^{1}, p^{0}\right)}{W S_{F}\left(y^{1}, y^{0}, x^{1}, x^{0}, w^{1}, w^{0}\right)} \times \frac{W_{F}}{P_{F}},
$$

which provides the relationship between the Konüs dual productivity index and the Fisher dual productivity index, which is the reciprocal of the Fisher price recovery index. Equality between the two productivity indexes is also a testable hypothesis.

As we show in the next section, relationship (28) is essential in deriving the desired relationship between the Konüs dual productivity index and a Malmquist productivity index, as well as between each of these theoretical productivity indexes and their empirical Fisher counterparts.

\section{The Relationship between Dual and Primal Productivity Indexes}

The input distance function provides the foundation for a Malmquist (1953) consumer standard of living index, which in our context is a producer input quantity index, given in geometric mean form by

$$
\begin{aligned}
X_{M}\left(y^{1}, y^{0}, x^{1}, x^{0}\right) & =\left[X_{M}^{0}\left(y^{0}, x^{1}, x^{0}\right) \times X_{M}^{1}\left(y^{1}, x^{1}, x^{0}\right)\right]^{1 / 2} \\
& =\left[\frac{D_{i}^{0}\left(y^{0}, x^{1}\right)}{D_{i}^{0}\left(y^{0}, x^{0}\right)} \times \frac{D_{i}^{1}\left(y^{1}, x^{1}\right)}{D_{i}^{1}\left(y^{1}, x^{0}\right)}\right]^{1 / 2} .
\end{aligned}
$$

The output distance function provides the foundation for an analogous producer output quantity index, given in geometric mean form by

$$
\begin{aligned}
Y_{M}\left(x^{1}, x^{0}, y^{1}, y^{0}\right) & =\left[Y_{M}^{0}\left(x^{0}, y^{1}, y^{0}\right) \times Y_{M}^{1}\left(x^{1}, y^{1}, y^{0}\right)\right]^{1 / 2} \\
& =\left[\frac{D_{O}^{0}\left(x^{0}, y^{1}\right)}{D_{O}^{0}\left(x^{0}, y^{0}\right)} \times \frac{D_{O}^{1}\left(x^{1}, y^{1}\right)}{D_{O}^{1}\left(x^{1}, y^{0}\right)}\right]^{1 / 2} .
\end{aligned}
$$

Diewert (1992) and, more explicitly, Bjurek (1996) defined a Malmquist productivity index as 


$$
\frac{Y_{M}\left(x^{1}, x^{0}, y^{1}, y^{0}\right)}{X_{M}\left(y^{1}, y^{0}, x^{1}, x^{0}\right)}=\left[\frac{D_{O}^{0}\left(x^{0}, y^{1}\right) / D_{O}^{0}\left(x^{0}, y^{0}\right)}{D_{i}^{0}\left(y^{0}, x^{1}\right) / D_{i}^{0}\left(y^{0}, x^{0}\right)} \times \frac{D_{O}^{1}\left(x^{1}, y^{1}\right) / D_{O}^{1}\left(x^{1}, y^{0}\right)}{D_{i}^{1}\left(y^{1}, x^{1}\right) / D_{i}^{1}\left(y^{1}, x^{0}\right)}\right]^{1 / 2} .
$$

We want to derive the relationship between the Konüs dual productivity index $W_{K}\left(y^{1}, y^{0}, w^{1}, w^{0}\right) / P_{K}\left(x^{1}, x^{0}, p^{1}, p^{0}\right)$ and the Malmquist productivity index $Y_{M}\left(x^{1}, x^{0}, y^{1}, y^{0}\right) / X_{M}\left(y^{1}, y^{0}, x^{1}, x^{0}\right)$. We have related the Konüs dual productivity index to profitability change in Section 2.3. We next relate the Malmquist productivity index to profitability change, and from these two relationships it is possible to relate Konüs dual and Malmquist productivity indexes. ${ }^{5}$

Grifell-Tatjé and Lovell $(2015,2016)$ have expressed profitability change as

$$
\frac{R^{1} / C^{1}}{R^{0} / C^{0}}=\frac{Y_{M}\left(x^{1}, x^{0}, y^{1}, y^{0}\right)}{X_{M}\left(y^{1}, y^{0}, x^{1}, x^{0}\right)} \times \frac{P_{F}}{W_{F}} \times \frac{Y M_{F}\left(x^{1}, x^{0}, p^{1}, p^{0}, y^{1}, y^{0}\right)}{X M_{F}\left(y^{1}, y^{0}, w^{1}, w^{0}, x^{1}, x^{0}\right)^{\prime}}
$$

and solving (33) for the Malmquist productivity index yields

$$
\frac{Y_{M}\left(x^{1}, x^{0}, y^{1}, y^{0}\right)}{X_{M}\left(y^{1}, y^{0}, x^{1}, x^{0}\right)}=\delta\left(y^{1}, y^{0}, x^{1}, x^{0}, p^{1}, p^{0}, w^{1}, w^{0}\right) \times \frac{W_{F}}{P_{F}}
$$

in which

$$
\delta\left(y^{1}, y^{0}, x^{1}, x^{0}, p^{1}, p^{0}, w^{1}, w^{0}\right)=\frac{\left(R^{1} / C^{1}\right) /\left(R^{0} / C^{0}\right)}{Y M_{F}\left(x^{1}, x^{0}, p^{1}, p^{0}, y^{1}, y^{0}\right) / X M_{F}\left(y^{1}, y^{0}, w^{1}, w^{0}, x^{1}, x^{0}\right)^{\prime}}
$$

and $Y M_{F}\left(x^{1}, x^{0}, p^{1}, p^{0}, y^{1}, y^{0}\right) / X M_{F}\left(y^{1}, y^{0}, w^{1}, w^{0}, x^{1}, x^{0}\right)$ is a Malmquist-Fisher quantity mix index analogous to the Shephard-Fisher price mix index in (27). Expression (34) provides the relationship between a Malmquist productivity index and a Fisher dual productivity index. And since $\frac{W_{F}}{P_{F}}=\frac{Y_{F}}{X_{F}} /\left[\frac{R^{1} / C^{1}}{R^{0} / C^{0}}\right]$ it follows that

$$
\frac{Y_{M}\left(x^{1}, x^{0}, y^{1}, y^{0}\right)}{X_{M}\left(y^{1}, y^{0}, x^{1}, x^{0}\right)}=\frac{Y_{F} / X_{F}}{Y M_{F}\left(x^{1}, x^{0}, p^{1}, p^{0}, y^{1}, y^{0}\right) / X M_{F}\left(y^{1}, y^{0}, w^{1}, w^{0}, x^{1}, x^{0}\right)^{\prime}}
$$

which provides the relationship between a Malmquist productivity index and a Fisher productivity index. The two productivity indexes are equal if and only if $Y M_{F}=X M_{F}$. However if variation in the quantity mixes is approximately offsetting, in the sense that any change in the output quantity mix has approximately the same effect on revenue 
as any change in the input quantity mix has on cost, then theoretical Malmquist and empirical Fisher productivity indexes are approximately equal.

Expressions (28) and (29) relate a theoretical Konüs dual productivity index to empirical primal and dual Fisher productivity indexes, and expressions (34) and (35) relate a theoretical Malmquist productivity index to empirical dual and primal Fisher productivity indexes. Conditions for equality between theoretical and empirical productivity indexes involve the behaviour of the data, expressed in terms of the trend in the margin of revenue over cost and trends in quantity and price mixes. No assumption of optimizing behaviour or about the structure of technology is required. In contrast, Färe and Grosskopf (1992) and Balk (1993) relate a theoretical inputoriented CCD Malmquist productivity index to a Fisher productivity index. They impose no restrictions on the behaviour of the data. Their conditions for equality involve optimizing behaviour, requiring allocative efficiency, both within and between periods. Finally, to complete the linkages among productivity indexes, Färe and Grosskopf (1996) relate the theoretical Malmquist and CCD Malmquist productivity indexes, with equality requiring restrictions on the structure of technology and the way it changes, namely constant returns to scale and inverse homotheticity. O'Donnell (2012) found constant returns to scale and the absence of technical change to suffice for equality, a requirement Mizobuchi (2016) relaxed to constant returns to scale and Hicks-neutral technical change.

Finally, equating expressions (35) and (28) yields the relationship between the Konüs dual and Malmquist productivity indexes

$$
\frac{W_{K}\left(y^{1}, y^{0}, w^{1}, w^{0}\right)}{P_{K}\left(x^{1}, x^{0}, p^{1}, p^{0}\right)}=\gamma\left(y^{1}, y^{0}, x^{1}, x^{0}, p^{1}, p^{0}, w^{1}, w^{0}\right) \times \frac{Y_{M}\left(x^{1}, x^{0}, y^{1}, y^{0}\right)}{X_{M}\left(y^{1}, y^{0}, x^{1}, x^{0}\right)}
$$

in which

$$
\begin{aligned}
\gamma\left(y^{1}, y^{0}, x^{1}, x^{0}, p^{1}, p^{0}, w^{1}, w^{0}\right) & \\
= & \frac{\frac{P S_{F}\left(x^{1}, x^{0}, y^{1}, y^{0}, p^{1}, p^{0}\right)}{W S_{F}\left(y^{1}, y^{0}, x^{1}, x^{0}, w^{1}, w^{0}\right)} \times \frac{Y M_{F}\left(x^{1}, x^{0}, p^{1}, p^{0}, y^{1}, y^{0}\right)}{X M_{F}\left(y^{1}, y^{0}, w^{1}, w^{0}, x^{1}, x^{0}\right)}}{\left(R^{1} / C^{1}\right) /\left(R^{0} / C^{0}\right)} .
\end{aligned}
$$

Thus equality of the Konüs dual and Malmquist productivity indexes requires the product of the Shephard-Fisher price mix index and the Malmquist-Fisher quantity mix index to equal profitability change. Even if the accounting identity holds, a condition satisfied by the Jorgenson and Griliches data, equality between Konüs dual and Malmquist productivity indexes is not guaranteed. Equality also would require any departure from price mix constancy to be offset by a reciprocal departure from quantity 
mix constancy. However as above the hypothesis that $\gamma\left(y^{1}, y^{0}, x^{1}, x^{0}, p^{1}, p^{0}, w^{1}, w^{0}\right)=$ 1 , and thus $\frac{W_{K}\left(y^{1}, y^{0}, w^{1}, w^{0}\right)}{P_{K}\left(x^{1}, x^{0}, p^{1}, p^{0}\right)}=\frac{Y_{M}\left(x^{1}, x^{0}, y^{1}, y^{0}\right)}{X_{M}\left(y^{1}, y^{0}, x^{1}, x^{0}\right)}$, is testable.

The relationships linking the two theoretical productivity indexes with the two empirical productivity indexes are collected in Table 1, in which each cell refers to an equation in this and the previous section.

\section{Insert Table 1 about here}

\section{Implementation}

The data set we use comprises a single time series, and so we resort to a global productivity index proposed by Pastor and Lovell (2005) defined on an intertemporal production set $T^{G}=\operatorname{conv}\left\{T^{1} \cup \ldots \cup T^{T}\right\}$ introduced by Tulkens and Vanden Eeckaut (1995). A global productivity index has the virtue of being a fixed base index, and therefore is circular, whereas a contemporaneous Malmquist productivity index is not, unless severe restrictions are imposed on the structure of technology and the way it changes (Färe and Grosskopf, 1996) or on the data and the way they change (Pastor and Lovell, 2019b).

With a global technology defined on a single time series of data, the dual productivity index is expressed as

$$
\frac{W_{K}^{G}\left(y^{t+1}, y^{t}, w^{t+1}, w^{t}\right)}{P_{K}^{G}\left(x^{t+1}, x^{t}, p^{t+1}, p^{t}\right)}=\frac{\left[W_{K}^{G}\left(y^{t}, w^{t+1}, w^{t}\right) \times W_{K}^{G}\left(y^{t+1}, w^{t+1}, w^{t}\right)\right]^{1 / 2}}{\left[P_{K}^{G}\left(x^{t}, p^{t+1}, p^{t}\right) \times P_{K}^{G}\left(x^{t+1}, p^{t+1}, p^{t}\right)\right]^{1 / 2}}
$$

and the primal productivity index is expressed as

$$
\frac{Y_{M}^{G}\left(x^{t+1}, x^{t}, y^{t+1}, y^{t}\right)}{X_{M}^{G}\left(y^{t+1}, y^{t}, x^{t+1}, x^{t}\right)}=\frac{\left[Y_{M}^{G}\left(x^{t}, y^{t+1}, y^{t}\right) \times Y_{M}^{G}\left(x^{t+1}, y^{t+1}, y^{t}\right)\right]^{1 / 2}}{\left[X_{M}^{G}\left(y^{t}, x^{t+1}, x^{t}\right) \times X_{M}^{G}\left(y^{t+1}, x^{t+1}, x^{t}\right)\right]^{1 / 2}}
$$

in which the superscript " $G$ " indicates the global technology consisting of data from all time periods, and $t=0,1, \ldots, T-1$.

Both productivity indexes are based on distance functions, and we use data envelopment analysis (DEA) (Charnes, Cooper and Rhodes, 1978; Banker, Charnes and Cooper, 1984) to estimate these distance functions. The envelopment program for the two distance functions comprising the dual Konüs input price index $W_{K}^{G}\left(y^{t+1}, y^{t}, w^{t+1}, w^{t}\right)$ is 
Envelopment Programs for $W_{K}^{G}\left(y^{t+1}, y^{t}, w^{t+1}, w^{t}\right)=D_{w}^{G}\left(y^{t}, w^{t+1}\right) / D_{w}^{G}\left(y^{t}, w^{t}\right)$

$$
\begin{aligned}
& {\left[D_{w}^{G}\left(y^{t}, w^{s}\right)\right]^{-1}=\min \mu} \\
& \text { Subject to } \\
& \qquad \begin{array}{rc}
\sum_{t=1}^{68} \lambda^{t} w_{n}^{t} \leqq \mu w_{n}^{s} & n=1, \ldots, 3 \\
& y_{m}^{t} \leqq \sum_{t=1}^{68} \lambda^{t} y_{m}^{t} \quad m=1, \ldots, 3 \\
& \sum_{t=1}^{68} \lambda^{t}=1, \lambda^{t} \geqq 0 \quad t=1, \ldots, 68
\end{array}
\end{aligned}
$$

$s=t+1$ in numerator, $s=t$ in denominator

and the envelopment program for the two distance functions comprising the dual Konüs output price index $P_{K}^{G}\left(x^{t+1}, x^{t}, p^{t+1}, p^{t}\right)$ is

$$
\begin{aligned}
& \text { Envelopment Programs for } P_{K}^{G}\left(x^{t+1}, x^{t}, p^{t+1}, p^{t}\right)=D_{p}^{G}\left(x^{t}, p^{t+1}\right) / D_{p}^{G}\left(x^{t}, p^{t}\right) \\
& \qquad\left[D_{p}^{G}\left(x^{t}, p^{s}\right)\right]^{-1}=\max v
\end{aligned}
$$

Subject to

$$
\begin{array}{cc}
v p_{m}^{s} \leqq \sum_{t=1}^{68} \lambda^{t} p_{m}^{t} & m=1, \ldots, 3 \\
\sum_{t=1}^{68} \lambda^{t} x_{n}^{t} \leqq x_{n}^{t} & n=1, \ldots, 3 \\
\sum_{t=1}^{68} \lambda^{t}=1, \lambda^{t} \geq 0 & t=1, \ldots, 68
\end{array}
$$

$s=t+1$ in numerator, $s=t$ in denominator

The envelopment programs for the distance functions comprising the primal Malmquist quantity indexes have the same structure, with input quantities replacing input prices in the first pair of programs, and output quantities replacing output prices in the second pair of programs.

\section{The Data and the Results}

Wang, Nehring and Mosheim (2018) provide background information generated by the US Department of Agriculture's Economic Research Service (ERS) on the productivity performance of US agriculture over the 68 year period 1948-2015. Using ERS 
aggregate quantity indexes, normalized to unity in 2005 , of total output and total farm input, Wang, Nehring and Mosheim report output growth of $170 \%$ and input growth of $7 \%$, from which they infer total factor productivity growth of $152 \%$, or $1.38 \%$ per annum. Using ERS aggregate price indexes of total output and total farm input, also normalized to unity in 2005 , we calculate input price growth of $788 \%$ and output price growth of $253 \%$, implying growth in the ratio of input prices to output prices of $152 \%$, or $1.38 \%$ per annum, exactly the same as the ERS estimate of total factor productivity growth. ${ }^{6}$

This data source also contains price and implicit quantity indexes, normalized to unity in 2005, of three outputs (livestock and products, crops, and other farm-related outputs) and three farm inputs (capital, labor, and intermediate goods). We use these indexes to estimate the two theoretical productivity indexes and to calculate the two empirical productivity indexes appearing in Table 1. The two decompositions of profitability change (which is one by construction) in expressions (27) and (33) are collected in Table 2 for the entire 1948-2015 period, and for peak-to-peak sub-periods used by the ERS. The decomposition of profitability change in expression (27), normalized to unity in 1949 and cumulated to 2015, is depicted in Figure 1.

\section{Insert Table 2 about here}

\section{Insert Figure 1 about here}

Over the entire period our Konüs-Shephard dual and the Malmquist primal productivity estimates bound the Fisher estimates very closely, with average annual growth rates of $W_{K}^{G} / P_{K}^{G}=1.42 \%>Y_{F} / X_{F}=1.38 \%>Y_{M}^{G} / X_{M}^{G}=1.13 \%$. The closeness of the two bounding estimates is due to the very small contributions of the two mix indexes, with average values of the price mix index $P S_{F}^{G} / W S_{F}^{G}=1.0007$ and average values of the quantity mix index $Y M_{F}^{G} / X M_{F}^{G}=1.0025$. Inserting the relevant mix indexes into expression (28) yields $W_{K}^{G} / P_{K}^{G}=1.0007 \times Y_{F} / X_{F}=1.0007 \times W_{F} / P_{F}$ and into expressions (34) and (35) yields $Y_{M}^{G} / X_{M}^{G}=1.0025 \times W_{F} / P_{F}=1.0025 \times Y_{F} / X_{F}$. Finally, from expression (36) the relation between dual Konüs and primal Malmquist productivity indexes is $W_{K}^{G} / P_{K}^{G}=1.0032 \times Y_{M}^{G} / X_{M}^{G}$. The small differences among the four productivity indexes occurs despite modest changes in the output mix, with crop production growing faster than livestock production, and "significant" changes in the input mix, with intermediate inputs and capital growing and land and labor declining, documented by the ERS. ${ }^{7}$

\section{Insert Figure 2 about here}

Figure 2 portrays three cumulative productivity indexes: two theoretical indexes, the dual Konüs index and the primal Malmquist index, and one empirical index, the Fisher index (primal and dual Fisher indexes are equal since the data satisfy 
zero annual profit by construction). The three indexes grow together until approximately 1982-83, when the Malmquist index begins to lag the other two indexes. This pattern suggests that most of the impact of the quantity mix index in equation (34), and the combined quantity mix index and price mix index in equation (36) has occurred since then. This has indeed occurred, with $Y M_{F} / X M_{F}(1984-2016)>Y M_{F} / X M_{F}$ (1949-1983) consistent with $Y_{M} / X_{M}<W_{F} / P_{F}$ during (1984-2016), and $Y M_{F} / X M_{F}$ (19842016) $>Y M_{F} / X M_{F}(1949-1983)$ and $P S_{F} / W S_{F}(1984-2016)>P S_{F} / W S_{F}(1949-1983)$ consistent with $Y_{M} / X_{M}<W_{K} / P_{K}$ during (1984-2016).

The period averages in Figure 2 conceal sub-period variability and dual/primal differences. Thus, for example, the Konüs dual productivity index grew at a rate of $4.4 \%$ during $1981-1990$ and declined at a rate of $1.6 \%$ during $1969-1973$, while the Malmquist primal productivity index grew at a rate of $4.5 \%$ during $1979-1981$ and declined at a rate of $0.2 \%$ during $1973-1979$. These period averages also conceal substantial annual productivity declines that occurred in 1978, 1983, 2009, 2014 and 2015. These findings are roughly in agreement with those of the ERS, which finds substantial sub-period productivity variation, with rapid productivity growth in 19791981 and productivity declines in 1973-1979 and 2007-2015. It also finds substantial annual productivity declines in 1978, 1983, 1995 and 2014 associated with transitory events such as energy shocks or supply shortages due to adverse weather conditions.

The cumulated results depicted in Figures 1 and 2 offer a compelling illustration of the distributive impacts of productivity growth emphasized by Siegel $(1955 ; 53)$ and Kendrick $(1961 ; 111)$. In US agriculture sustained productivity growth meant that by 2015 input prices were over 2.5 times higher relative to output prices than they were in 1949.

\section{Insert Tables 3 and 4 about here}

Tables 3 and 4 decompose the sources of profitability change results in Table 2 into the sources of revenue change and the sources of cost change. In Table 3 theoretical and empirical indexes agree that output price growth has dominated output quantity growth as the prime source of revenue growth, with $P_{K}^{G}>Y_{F}$ and $P_{F}>Y_{M}^{G}$. Table 3 tells a similar story: input price growth has been the primary driver of cost growth, with $W_{K}^{G}>X_{F}$ and $W_{F}>X_{M}^{G}$.

\section{Conclusions}

In this paper we propose a new dual productivity index based on the work of Konüs and Shephard. The index exploits the fact, noted by Shephard, that the cost functions Konüs used to define a cost of living index in quantity space, with input quantities as the choice variables, can be re-interpreted as input distance functions in price space, with input prices as the choice variables. These input distance functions can then be 
used to construct an input price index. Similarly revenue functions can be reinterpreted as output distance functions in output price space and used to construct an output price index. This leads to the definition of a dual productivity index as the ratio of an input price index to an output price index.

We have derived the relationship between our Konüs-Shephard dual productivity index and a Malmquist primal productivity index, and we have demonstrated that the two are not generally equal. The relationship between the two depends on two features of the underlying data: the trend in the margin of revenue over cost, and the trends in the output quantity mix and the input quantity mix. We have also shown that the dual and primal theoretical indexes are not generally equal to their Fisher empirical counterparts, with the relationships depending on the same features of the underlying data.

Our new dual productivity index is a theoretical index, in contrast to the empirical Fisher index, and so must be estimated rather than calculated. We have used a time series of US agricultural data to estimate our dual and primal productivity indexes, and to calculate Fisher primal and dual productivity indexes. Although no two productivity indexes are equal, all four have approximately the same magnitude. This finding is attributable to two features of the data mentioned above: the margin is unity by construction (i.e., the accounting identity is satisfied in all years), and departures of the output price mix from constancy have been approximately offset by departures of the input price mix from constancy, and similarly for output and input quantity mixes.

We conclude by recalling that Fourastié motivated a dual approach to productivity measurement by arguing that in some circumstances prices are easier to measure, or measured more accurately, than quantities. Later Hsieh estimated primal and dual productivity indexes for four East Asian countries, and found the two to diverge dramatically in Singapore, with estimated dual productivity growth and primal productivity decline. He attributed this divergence to a significant overstatement of investment spending in the Singapore national accounts that artificially depressed estimated primal productivity change.

However all previous dual and indirect productivity indexes cited in Section 1 rely on quantity data, typically in the form of output revenue shares used to weight output price changes and input cost shares used to weight input price changes. Indeed our dual productivity index uses output quantities in the construction of a dual input price index and input quantities in the construction of a dual output price index. This universal reliance on quantity data requires either a belief in the accuracy of national (or sectoral, or business) account quantity data, or a conviction in the inaccuracy of such data combined with a willingness to develop and defend alternative quantity data, as Hsieh has done. An alternative approach to generating and defending alternative quantity data would exploit the multiplier duals to the DEA envelopment programs in Section 4. These multiplier programs provide shadow output quantities and shadow input quantities, which may be compared to observed quantity data as a credibility check. 
This dilemma suggests that a logical extension of the dual productivity index introduced in this paper would be the development of an alternative theory-based dual productivity index that is entirely independent of quantity data. Such an index would be analogous to a Malmquist productivity index, which is entirely independent of price data. Our dual productivity index is independent of quantity data if and only if production technology is inversely homothetic. It would be desirable to develop a theory-based dual productivity index independent of quantity data that does not rely on such an unrealistic assumption about the structure of production technology. 


\section{References}

Aiyar, S., and C.-J. Dalgaard (2005), "Total Factor Productivity Revisited: A Dual Approach to Development Accounting," IMF Staff Papers 52, 81-102.

Balk, B. (1993), "Malmquist Productivity Indexes and Fisher Ideal Indexes: Comment," Economic Journal 103, 680-682.

Banker, R. D., A. Charnes and W. W. Cooper (1984), "Some Models for Estimating Technical and Scale Inefficiencies in Data Envelopment Analysis," Management Science 30, 1078-1092.

Bjurek, H. (1996), "The Malmquist Total Factor Productivity Index," Scandinavian Journal of Economics 98, 303-313.

Caves, D. W., L. R. Christensen and W. E. Diewert (1982), "The Economic Theory of Index Numbers and the Measurement of Input, Output, and Productivity," Econometrica 50, 1393-1414.

Charnes, A., W. W. Cooper and E. Rhodes (1978), "Measuring the Efficiency of Decision-Making Units," European Journal of Operational Research 2, 429-444.

Davis, H. S. (1955), Productivity Accounting. Philadelphia: University of Pennsylvania Press.

Dayre, J. (1951), "La Productivité Intégrale du Travail et sa Mesure," Revue d'Économie Politique 61, 665-675.

Diewert, W. E. (1992), "Fisher Ideal Output, Input and Productivity Indexes Revisited," Journal of Productivity Analysis 3, 211-248.

Eldor, D., and E. Sudit (1981), "Productivity-based Financial Net Income Analysis," Omega 9, 605-611.

Evans, W. D. (1947), "Recent Productivity Trends and their Implications," Journal of the American Statistical Association 42, 211-223.

Färe, R. (1984), "The Dual Measurement of Efficiency," Zeitschrift für Nationalökonomie 44, 283-288.

Färe, R., and S. Grosskopf (1992), "Malmquist Productivity Indexes and Fisher Ideal Indexes," Economic Journal 102, 158-160.

Färe, R., and S. Grosskopf (1994), Cost and Revenue Constrained Production. Bilkent University Lecture Series Vol.4. New York: Springer-Verlag.

Färe, R., and S. Grosskopf (1996), Intertemporal Production Frontiers: With Dynamic DEA. Boston: Kluwer Academic Publishers.

Färe, R., S. Grosskopf and C. A. K. Lovell (1992), "Indirect Productivity Measurement," Journal of Productivity Analysis 2, 283-298. 
Fernald, J., and B. Neiman (2011), "Growth Accounting with Misallocation: Or, Doing Less with More in Singapore," American Economic Journal: Macroeconomics 3, 2974.

Fourastié, J. (1957), Productivity, Prices and Wages. Paris: European Productivity Agency.

Fourastié, J. (1962), Documents Pour l'Histoire et la Théorie des Prix. 2 Vols. Centre d'Études Économiques. Paris: Libraire Armand Colin.

Georgescu-Roegen, N. (1951), "The Aggregate Linear Production Function and its Applications to von Neumann's Economic Model," Chapter 4 in T. C. Koopmans (ed.), Activity Analysis of Production and Allocation. New York: Wiley. Pp. 98-115.

Grifell-Tatjé, E., and C. A. K. Lovell (2015), Productivity Accounting: The Economics of Business Performance. New York: Cambridge University Press.

Grifell-Tatjé, E., and C. A. K. Lovell (2016), "Exact Relationships between Fisher Indexes and Theoretical Indexes," Chapter 5 in J. Aparicio, C. A. K. Lovell and J. T. Pastor, eds., Advances in Efficiency and Productivity. Springer International Series in Operations Research \& Management Science, Vol. 249.

Hsieh, C.-T. (2002), "What Explains the Industrial Revolution in East Asia? Evidence From the Factor Markets," American Economic Review 92, 502-526.

Jorgenson, D. W., and Z. Griliches (1967), "The Explanation of Productivity Change," Review of Economic Studies 34, 249-283.

Kendrick, J. W. (1961), Productivity Trends in the United States. Princeton, NJ: Princeton University Press.

Konüs, A. A. (1939 [1924]), "The Problem of the True Index of the Cost of Living," Econometrica 7, 10-39.

Malmquist, S. (1953), "Index Numbers and Indifference Surfaces," Trabajos de Estadistica 4, 209-242.

Mizobuchi, H. (2016), "Productivity Indexes under Hicks Neutral Technical Change," Journal of Productivity Analysis 48, 63-68.

O'Donnell, C. J. (2012), "An Aggregate Quantity Framework for Measuring and Decomposing Productivity Change," Journal of Productivity Analysis 38, 255-272.

Pastor, J. T., and C. A. K. Lovell (2005), "A Global Malmquist Productivity Index," Economics Letters 88, 266-271.

Pastor, J. T., and C. A. K. Lovell (2019a), "Local Circularity of Six Classic Price Indexes," Centre for Efficiency and Productivity Analysis, University of Queensland WP01/2019 https://economics.uq.edu.au/files/12943/WP012019.pdf 
Pastor, J. T., and C. A. K. Lovell (2019b), "Malmquist Circularity Conditions: Hicks Neutrality versus Local Circularity," presentation at the European Workshop on Efficiency and Productivity Analysis. http://www.ewepa.org/programme/

Puiseux, L., and P. Bernard (1965), "Les Progrès de Productivité et Leur Utilisation a l'Électricité de France de 1952 a 1962," Études et Conjoncture (Janvier), 77-98.

Puiseux, L., and P. Bernard (1966), "Essai de Mesure de la Productivité Globale des Facteurs a l'Électricité de France de 1954 a 1962," Revue Française de L'Energie 180 (Mai), 421-440.

Roeger, W. (1995), "Can Imperfect Competition Explain the Difference between Primal and Dual Productivity Measures? Estimates for U.S. Manufacturing," Journal of Political Economy 103, 316-330.

Rostás, L. (1948), Comparative Productivity in British and American Industry. Cambridge : Cambridge University Press.

Roy, R. (1953), "Remarques Sur la Notion de Productivité," Journal de la Société Statistique de Paris 94, 231-243.

Shapiro, M. D. (1987), "Are Cyclical Fluctuations in Productivity Due More to Supply Shocks or Demand Shocks?" American Economic Review 77, 118-24.

Shephard, R. W. (1970), Theory of Cost and Production Functions. Princeton NJ: Princeton University Press.

Shephard, R. W. (1974), Indirect Production Functions. Meisenheim Am Glan: Verlag Anton Hain.

Siegel, I. H. (1955), "Aspects of Productivity Measurement and Meaning," Chapter III in European Productivity Agency (1955), Productivity Measurement I. Concepts. Paris: Organisation for European Economic Co-operation.

Siegel, I. H. (1961), "On the Design of Consistent Output and Input Indexes for Productivity Measurement," Chapter 1 in Output, Input and Productivity Measurement, National Bureau of Economic Research Studies in Income and Wealth, Volume 25. Princeton, NJ: Princeton University Press. Pp. 23-46.

Tulkens, H, and P. Vanden Eeckaut (1995), "Non-Parametric Efficiency, Progress and Regress Measures for Panel Data: Methodological Aspects," European Journal of Operational Research 80, 474-499.

Vincent, L. A. (1961), "The Main Formulae for Productivity Measurement in a National Economy or Sector," Productivity Measurement Review 25, 5-17.

Wang, S. L., R. Nehring and R. Mosheim (2018), "Agricultural Productivity Growth in the United States: 1948-2015," Economic Research Service, United States Department of Agriculture. https://www.ers.usda.gov/amberwaves/2018/march/agricultural-productivity-growth-in-the-united-states-1948-2015/ 


\begin{tabular}{|c|c|c|c||c|c|}
\hline \multirow{2}{*}{ Productivity Indexes } & \multicolumn{2}{|c||}{ Theoretical } & \multicolumn{2}{c|}{ Empirical } \\
\cline { 3 - 6 } & $\mathrm{W}_{\mathrm{K}} / \mathrm{P}_{\mathrm{K}}$ & $\mathrm{Y}_{\mathrm{M}} / \mathrm{X}_{\mathrm{M}}$ & $\mathrm{W}_{\mathrm{F}} / \mathrm{P}_{\mathrm{F}}$ & $\mathrm{Y}_{\mathrm{F}} / \mathrm{X}_{\mathrm{F}}$ \\
\hline \hline \multirow{3}{*}{ Theoretical } & $\mathrm{W}_{\mathrm{K}} / \mathrm{P}_{\mathrm{K}}$ & & $(36)$ & $(29)$ & $(28)$ \\
\cline { 2 - 6 } & $\mathrm{Y}_{\mathrm{M}} / \mathrm{X}_{\mathrm{M}}$ & $(36)$ & & $(34)$ & $(35)$ \\
\hline \multirow{3}{*}{ Empirical } & $\mathrm{W}_{\mathrm{F}} / \mathrm{P}_{\mathrm{F}}$ & $(29)$ & $(34)$ & & $(29)$ \\
\cline { 2 - 6 } & $\mathrm{Y}_{\mathrm{F}} / \mathrm{X}_{\mathrm{F}}$ & $(28)$ & $(35)$ & $(29)$ & \\
\hline
\end{tabular}

Table 1 Relationships Linking Four Productivity Indexes 


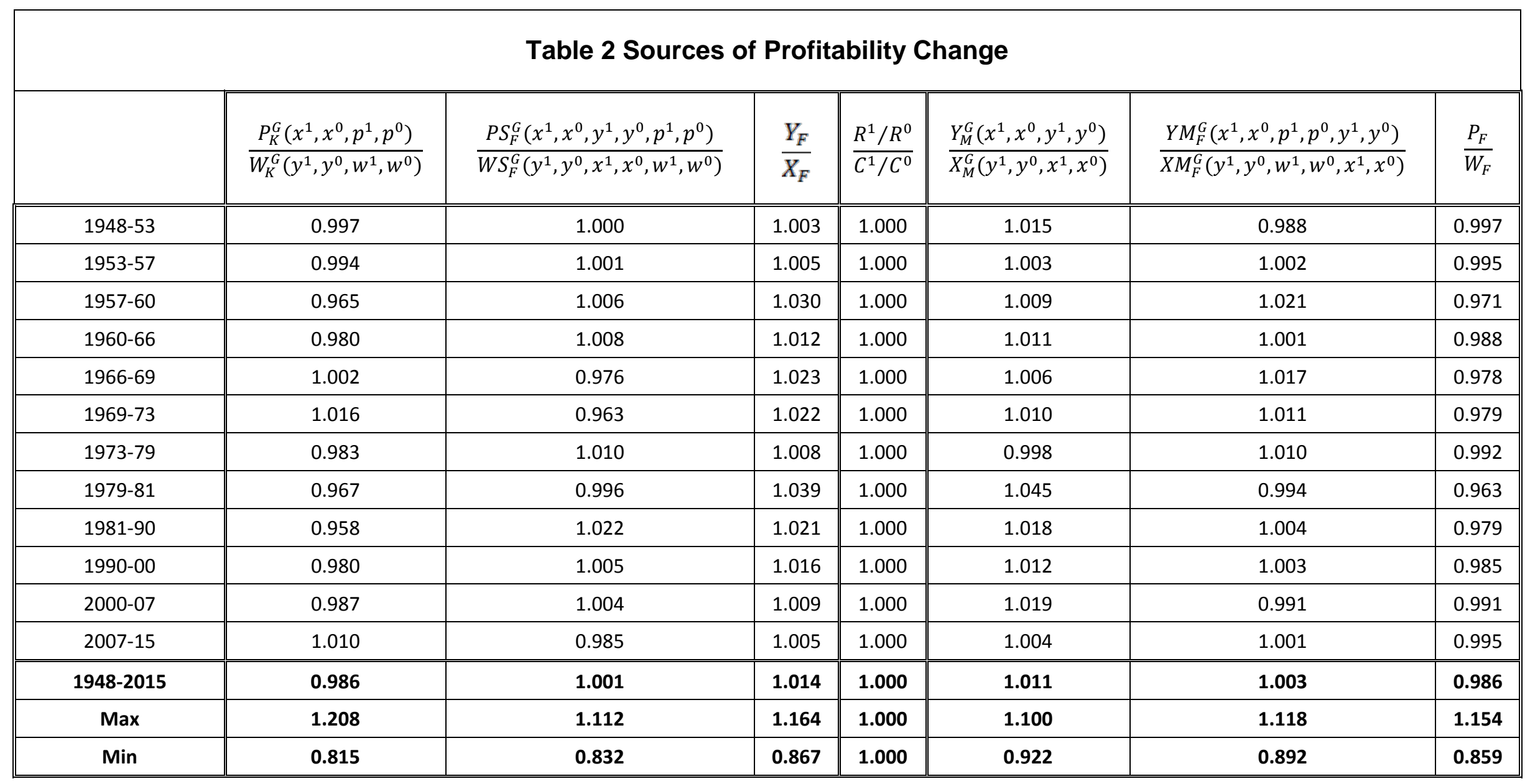




\begin{tabular}{|c|c|c|c|c|c|c|c|}
\hline \multicolumn{8}{|c|}{ Table 3 Sources of Revenue Change } \\
\hline & $P_{K}^{G}\left(x^{1}, x^{0}, p^{1}, p^{0}\right)$ & $P S_{F}^{G}\left(x^{1}, x^{0}, y^{1}, y^{0}, p^{1}, p^{0}\right)$ & $Y_{F}$ & $R^{1} / R^{0}$ & $Y_{M}^{G}\left(x^{1}, x^{0}, y^{1}, y^{0}\right)$ & $Y M_{F}^{G}\left(x^{1}, x^{0}, p^{1}, p^{0}, y^{1}, y^{0}\right)$ & $P_{F}$ \\
\hline $1948-53$ & 0.997 & 0.975 & 1.010 & 0.982 & 1.019 & 0.991 & 0.972 \\
\hline $1953-57$ & 1.003 & 0.973 & 1.005 & 0.981 & 1.001 & 1.004 & 0.977 \\
\hline $1957-60$ & 1.008 & 0.993 & 1.038 & 1.039 & 1.013 & 1.024 & 1.001 \\
\hline $1960-66$ & 1.024 & 1.008 & 1.011 & 1.044 & 1.010 & 1.001 & 1.032 \\
\hline $1966-69$ & 1.028 & 0.974 & 1.023 & 1.024 & 1.007 & 1.016 & 1.001 \\
\hline $1969-73$ & 1.106 & 1.014 & 1.025 & 1.150 & 1.017 & 1.009 & 1.122 \\
\hline $1973-79$ & 1.067 & 0.979 & 1.025 & 1.069 & 1.017 & 1.007 & 1.044 \\
\hline $1979-81$ & 0.995 & 1.042 & 1.026 & 1.064 & 1.027 & 0.999 & 1.037 \\
\hline $1981-90$ & 1.011 & 0.997 & 1.008 & 1.016 & 1.009 & 0.999 & 1.008 \\
\hline $1990-00$ & 0.998 & 0.996 & 1.018 & 1.011 & 1.017 & 1.001 & 0.993 \\
\hline $2000-07$ & 1.036 & 1.008 & 1.010 & 1.056 & 1.014 & 0.996 & 1.045 \\
\hline $2007-15$ & 1.027 & 0.999 & 1.007 & 1.033 & 1.013 & 0.994 & 1.025 \\
\hline 1948-2015 & 1.024 & 0.995 & 1.015 & 1.034 & 1.013 & 1.002 & 1.019 \\
\hline Max & 1.304 & 1.097 & 1.140 & 1.429 & 1.077 & 1.118 & 1.364 \\
\hline Min & 0.867 & 0.899 & 0.860 & 0.867 & 0.965 & 0.891 & 0.880 \\
\hline
\end{tabular}




\begin{tabular}{|c|c|c|c|c|c|c|c|}
\hline \multicolumn{8}{|c|}{ Table 4 Sources of Cost Change } \\
\hline & $W_{K}^{G}\left(y^{1}, y^{0}, w^{1}, w^{0}\right)$ & $W S_{F}^{G}\left(y^{1}, y^{0}, x^{1}, x^{0}, w^{1}, w^{0}\right)$ & $X_{F}$ & $C^{1} / C^{0}$ & $X_{M}^{G}\left(y^{1}, y^{0}, x^{1}, x^{0}\right)$ & $X M_{F}^{G}\left(y^{1}, y^{0}, w^{1}, w^{0}, x^{1}, x^{0}\right)$ & $W_{F}$ \\
\hline $1948-53$ & 1.000 & 0.975 & 1.007 & 0.982 & 1.004 & 1.002 & 0.975 \\
\hline $1953-57$ & 1.010 & 0.972 & 1.000 & 0.981 & 0.998 & 1.002 & 0.982 \\
\hline $1957-60$ & 1.045 & 0.986 & 1.008 & 1.039 & 1.005 & 1.003 & 1.031 \\
\hline $1960-66$ & 1.045 & 1.000 & 0.999 & 1.044 & 0.999 & 1.000 & 1.045 \\
\hline $1966-69$ & 1.026 & 0.998 & 1.000 & 1.024 & 1.001 & 0.999 & 1.024 \\
\hline $1969-73$ & 1.089 & 1.053 & 1.004 & 1.150 & 1.006 & 0.997 & 1.146 \\
\hline $1973-79$ & 1.085 & 0.969 & 1.017 & 1.069 & 1.020 & 0.997 & 1.052 \\
\hline $1979-81$ & 1.029 & 1.046 & 0.988 & 1.064 & 0.983 & 1.005 & 1.077 \\
\hline $1981-90$ & 1.054 & 0.976 & 0.987 & 1.016 & 0.991 & 0.996 & 1.029 \\
\hline $1990-00$ & 1.018 & 0.991 & 1.002 & 1.011 & 1.005 & 0.998 & 1.009 \\
\hline $2000-07$ & 1.050 & 1.004 & 1.001 & 1.056 & 0.995 & 1.006 & 1.055 \\
\hline $2007-15$ & 1.017 & 1.014 & 1.002 & 1.033 & 1.009 & 0.993 & 1.031 \\
\hline 1948-2015 & 1.039 & 0.995 & 1.001 & 1.034 & 1.002 & 0.999 & 1.033 \\
\hline Max & 1.188 & 1.196 & 1.067 & 1.429 & 1.085 & 1.055 & 1.400 \\
\hline Min & 0.836 & 0.884 & 0.932 & 0.867 & 0.957 & 0.963 & 0.856 \\
\hline
\end{tabular}




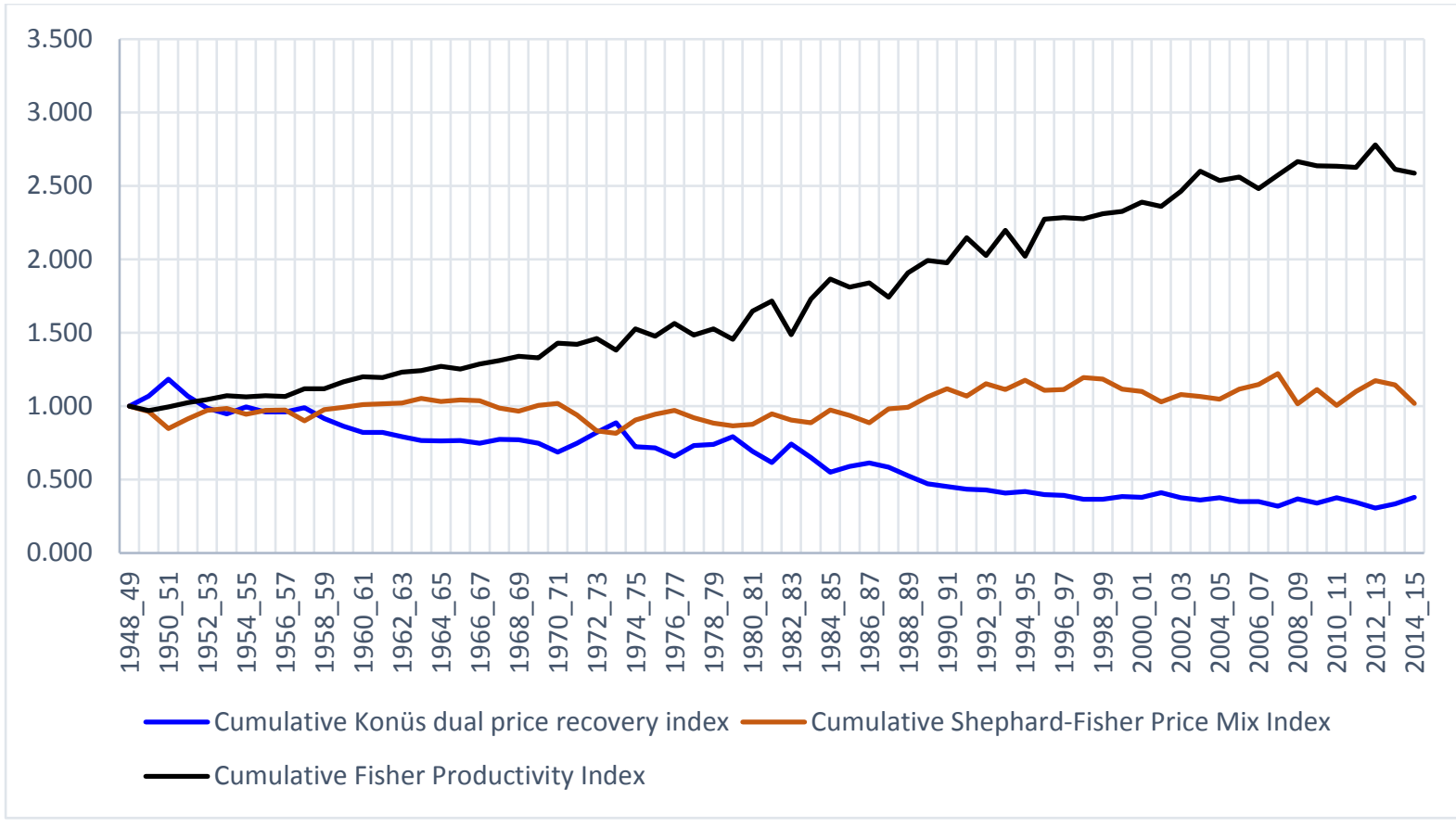

Figure 1 Sources of Profitability Change 


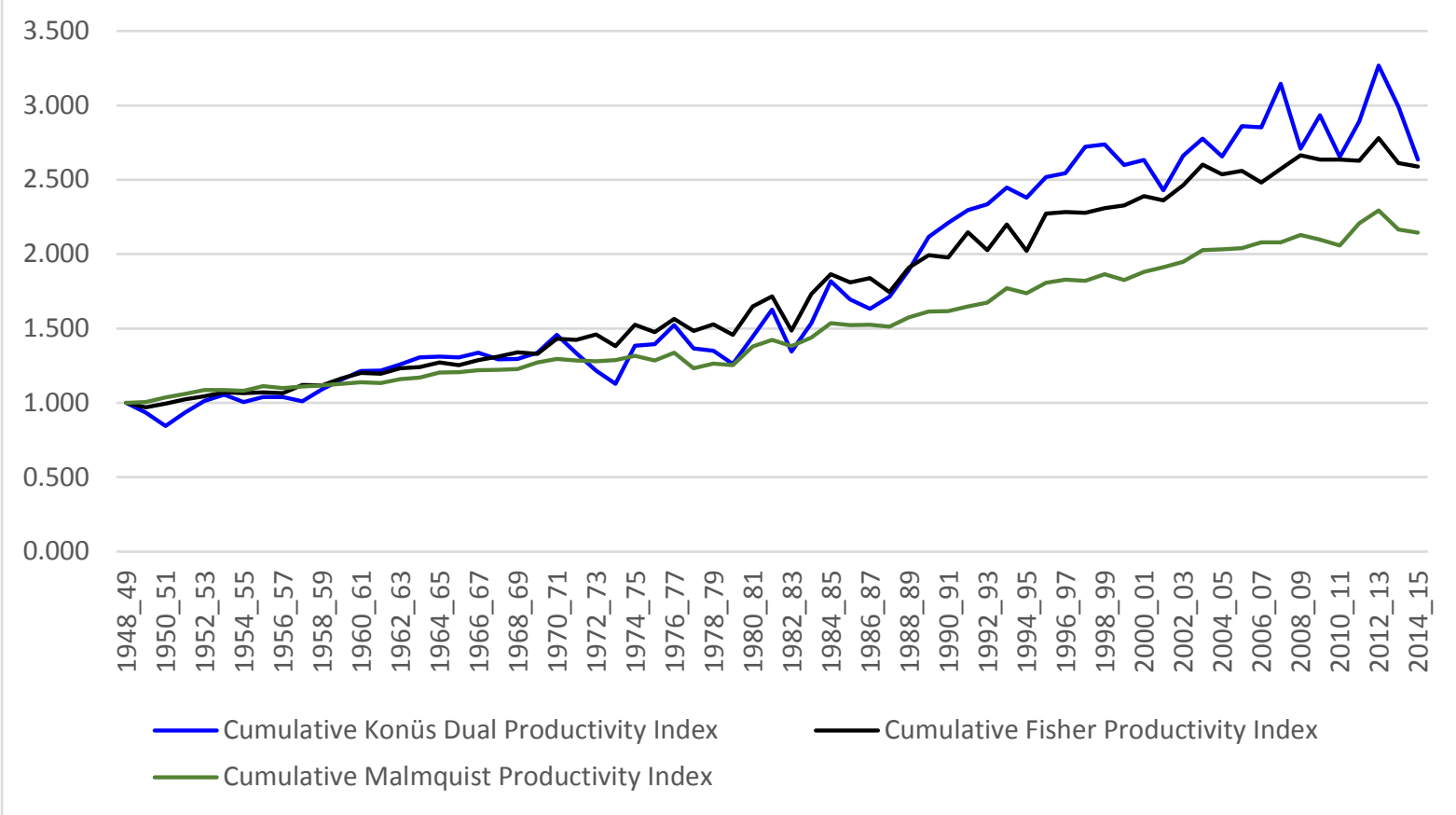

Figure 2 Three Cumulative Productivity Indexes 


\section{Endnotes}

${ }^{1}$ Davis also emphasized the generation and distribution of non-pecuniary benefits such as improved product quality and improved working conditions.

${ }^{2}$ Fourastié acknowledged Rostas (1948), Dayre (1951) and Roy (1953) as having inspired his indirect productivity index.

${ }^{3} \mathrm{~A}$ special case of a price recovery index is a terms of trade index, the ratio of an export price index to an import price index.

${ }^{4}$ A similar sufficiency condition holds for all geometric mean functions. For example, Pastor and Lovell (2019a) have shown that a Fisher price index can be circular even if neither of its Laspeyres and Paasche components is circular.

${ }^{5}$ The Malmquist productivity index in (32) is simultaneously output- and input-oriented. This desirable feature distinguishes it from an alternative Malmquist productivity index introduced by Caves, Christensen and Diewert (1982), which is either output-oriented or input-oriented, but not both.

${ }^{6}$ Equality of the ERS implicit quantity-based and price-based productivity indexes is consistent with the data satisfying zero annual profit by construction and the use of Fisher indexes. The ERS agricultural productivity data are publicly available, and can be accessed at https://www.ers.usda.gov/data-products/agricultural-productivity-in-the-us/.

${ }^{7}$ See https://www.ers.usda.gov/webdocs/publications/45387/53417_err189.pdf?v=0. 